and asymptomatic smokers. Eur Respir $J$ 2005; 26: 835-845.

2 Willemse B, Lesman-Leegte I, Timens T, Postma D, ten Hacken N. High cessation rates of cigarette smoking in subjects with and without COPD. Chest 2005; 128: 3685-3687.
3 Larimer ME, Palmer RS, Marlatt GA. Relapse prevention. An overview of Marlatt's cognitive behavioural model. Alcohol Res Health 1999; 23: 151-160.

DOI: $10.1183 / 09031936.06 .00004006$

\title{
A day at the European Respiratory Society Congress: passive smoking influences both outdoor and indoor air quality
}

\section{To the Editors:}

Outdoor and indoor air quality is a well known determinant of human health [1]. Environmental tobacco smoke (ETS) is a recognised risk factor for respiratory diseases [2] and the most important source of indoor particulate matter (PM) pollution [3]. In recent years, several countries have issued smoking policy rules to protect nonsmoking people from ETS with a good compliance [4]. This year, the European Respiratory Society (ERS) Congress was held in Copenhagen (Denmark), a country where, like many others, comprehensive anti-smoking rules are not yet fully endorsed [5]. In fact, although smoking has been restricted in state-owned governmental premises since 1988, the legislation doesn't apply to the hospitality industry or to workplaces in the private sector. The ERS has made the case of passive smoking one of utmost importance for respiratory prevention [6]. Congress participants were advised to refrain from smoking both inside and in front of the Copenhagen Congress venue at the Bella Center, which was indicated by signs stating the following: "Tobacco is the major cause of lung disease. Please refrain from smoking in and in front of the Congress venue, including meeting rooms, the exhibition, poster areas, restrooms, restaurants and bars." The ERS Congress represented a good opportunity for air quality measurement and comparisons in relation to ETS pollution. PM2.5, as a representative marker of outdoor pollution [1] and as a surrogate of ETS [7], was measured in different places in the city, in the proximity of the Bella Center and inside the Bella Center, and compared with official 24-h urban backgrounds.

PM2.5 measurements were carried out on the third day of the Congress (September 17, 2005) from the morning to late in the evening with time-tabled records of the place of measurements. We measured PM concentrations sequentially in the Congress car parking place (open space), inside the Bella Center, outdoors in front of the Bella Center with smokers under a roof (18 smokers during a measurement time of $35 \mathrm{~min}$ ), along the motorway to the city centre, and inside a Copenhagen restaurant where smoking was allowed. Official outdoor PM2.5 values for the same day were taken for comparison from an urban background location in Copenhagen (H.C. Ørsted Institute) belonging to the Danish Air Quality Monitoring Programme [8].
PM2.5 measurements were carried out by means of model AEROCET 531 (Metone Instruments Inc., Grants Pass, OR, USA), a hand-held laser-operated monitor of particle size and mass concentration with a 2-min sampling time. The instrument had been pre-calibrated using a reference gravimetric system. The weather was cloudy and with a light breeze, with the temperature ranging $17-27^{\circ} \mathrm{C}$ and the relative humidity $44-74 \%$. For each site, a minimum of eight consecutive measurements for a total of $16 \mathrm{~min}$ were taken. US-EPA air quality index (AQI) was chosen as a reference [9]. The official outdoor PM2.5 values at the urban background location were measured with TEOM technology (TaperedElement Oscillating Microbalance; Rupprecht \& Patashnick Co. Inc., Albany, NY, USA).

Mean \pm SEM PM2.5 records are reported in figure 1. With reference to time-sequence of measurements, PM2.5 complied

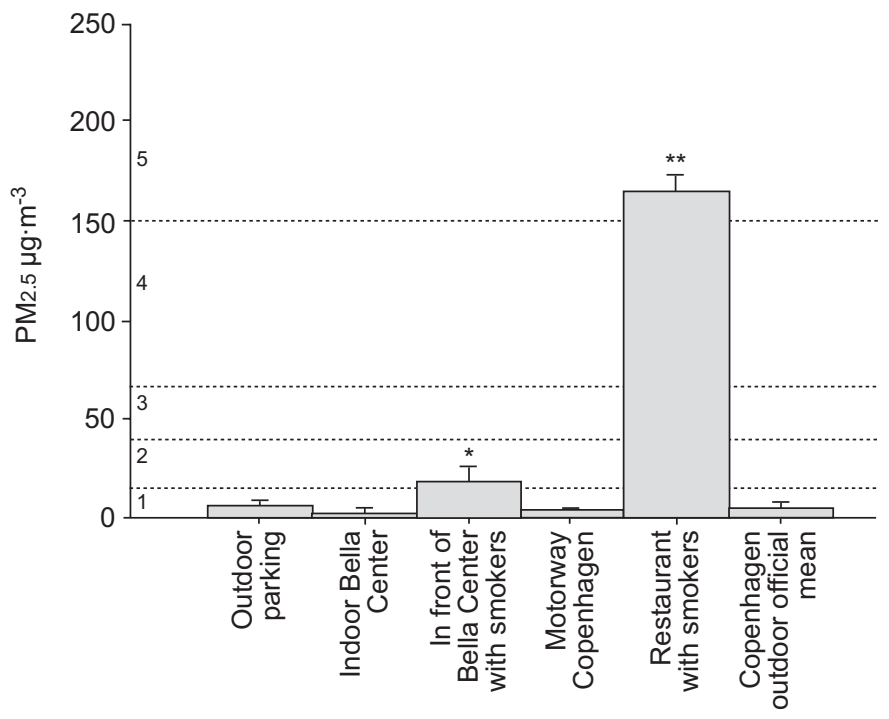

FIGURE 1. Comparison of particulate matter (PM2.5) concentrations at different sites during the third day of the European Respiratory Society Copenhagen Congress, 2005. $\cdots$ : air quality index break-points, which correspond to the following. 5: very unhealthy; 4 : unhealthy; 3 : unhealthy for sensitive groups; 2: moderate; 1: good. *: $p<0.05$ as compared with outdoor, indoor, motorway and official mean; $* *: p<0.001$ as compared with outdoor, indoor, motorway and official mean. 
with good AQI according to US-EPA $\left(<12.5 \mu \mathrm{g} \cdot \mathrm{m}^{-3}\right)$ in the car parking area and inside the Bella Center, with a level of $6.0 \pm 1.7$ and $3.0 \pm 0.9 \mu \mathrm{g} \cdot \mathrm{m}^{-3}$, respectively. Peak values were $12.5 \mu \mathrm{g} \cdot \mathrm{m}^{-3}$ and $12.0 \mu \mathrm{g} \cdot \mathrm{m}^{-3}$, respectively. However, outside in front of the Bella Center with smokers, mean PM2.5 was $17.8 \pm 7.5 \mu \mathrm{g} \cdot \mathrm{m}^{-3}$ with a peak of $98.9 \mu \mathrm{g} \cdot \mathrm{m}^{-3}(\mathrm{p}<0.03$, as compared with inside the venue), which is a step down in AQI. PM2.5 along the motorway was only $4.6 \pm 0.7 \mu \mathrm{g} \cdot \mathrm{m}^{-3}$ with a peak value of $8.7 \mu \mathrm{g} \cdot \mathrm{m}^{-3}$. Inside the restaurant, high concentrations of PM2.5 were found $\left(165.1 \pm 8.5 \mu \mathrm{g} \cdot \mathrm{m}^{-3}\right)$ with a peak value of $372.2 \mu \mathrm{g} \cdot \mathrm{m}^{-3}$, with a "very unhealthy" AQI. Official outdoor PM2.5 mean \pm SEM recorded in the town for the time interval of all the measurements was $5.7 \pm 0.4 \mu \mathrm{g} \cdot \mathrm{m}^{-3}$. Overall, mean values observed with smokers in front of the Bella Center and inside the restaurant were significantly higher than the outdoor parking place, indoor Bella Center, motorway and Copenhagen outdoor official data $(p<0.05$ and $p<0.001$, respectively).

Indoor and outdoor air quality monitoring through an entire day showed that in a country where outdoor air quality is generally good, as in Denmark, the presence of ETS worsens both indoor and outdoor PM concentrations. In the restaurant with smokers we observed very high PM2.5 levels, with an AIQ classified as "very unhealthy", as reported by previous studies [7]. PM also reached significant values outdoors where smokers gathered to smoke, confirming previous field surveys at outdoor patios [10]. By appreciating this issue, ERS organisers advised participants not to smoke in front of the Congress venue, a suggestion that also implies coherence with doctor's role model, an issue that still deserves attention.

Understanding the importance of indoor versus outdoor pollution and the issue of environmental tobacco smoke as both an indoor and outdoor pollutant can contribute to a better knowledge of environmental tobacco smoke exposure risk.

\section{ACKNOWLEDGEMENTS}

The authors are grateful to G. Viegi for his helpful discussion.

\section{R. Boffi ${ }^{*}$, A. Ruprecht*, R. Mazza*, M. Ketzel ${ }^{\#}$ and \\ G. Invernizzi*}

*Tobacco Control Unit, National Cancer Institute/SIMG-Italian College of GPs, Milan, Italy, and "National Environmental Research Institute, Roskilde, Denmark.

\section{REFERENCES}

1 Kunzli N. The public health relevance of air pollution abatement. Eur Respir J 2002; 20: 198-209.

2 Viegi G, Simoni M, Scognamiglio A, et al. Indoor air pollution and airway disease. Int J Tuberc Lung Dis 2004; 8: 1401-1415.

3 Repace JL, Lowrey AH. Indoor air pollution, tobacco smoke, and public health. Science 1980; 208: 464-472.

4 Gallus S, Zuccaro P, Colombo P, et al. Effects of new smoking regulations in Italy. Ann Oncol 2006; 17: 346-347.

5 Denmark Law about Smoke-free Environments on Public Premises; means of transportation and the like. Law nr.436 of 06/01/1995. Available online: http://apps.nccd.cdc.gov/ nations/legislation/TextFiles/Denmark_13.htm. Date last accessed: December 2005. Date last updated: November 2005.

6 Smoke Free Europe Conference 2005. http://www.ersnet. org/ers/lr/browse/default.aspx?id_dossier $=31552$. Date last accessed: December 2005. Date last updated: December 2005.

7 Invernizzi G, Ruprecht A, Mazza R, et al. Real-time measurement of indoor particulate matter originating from environmental tobacco smoke: a pilot study. Epidemiol Prev 2002; 26: 2-6.

8 Kemp K, Ellermann T, Palmgren F, Wåhlin P, Berkowicz R. Jørgen Brandt 2005: The Danish Air Quality Monitoring Programme. Annual summary for 2004. National Environmental Research Institute (NERI), Roskilde Denmark. NERI Technical Report No. 544. Link for report: http: $\backslash \backslash$ technical-reports.dmu.dk. Link for recent data: http:// www.dmu.dk/atmosphericenvironment/byer/forside.htm. Date last accessed: December 2005. Date last updated: December 2005.

9 Guideline for reporting of daily air quality-air quality index (AQI). United States Office of Air Quality EPA-454/ R-99-010 Environmental Protection Planning and Standards July 1999.

10 Repace J. Measurements of outdoor air pollution from secondhand smoke on the UMBC campus. http:// www.repace.com/pdf/outdoorair.pdf. Date last accessed: December 2005. Date last updated: November 2005.

DOI: 10.1183/09031936.06.00148505

\section{COPD: an inhaled corticosteroid-resistant, oral corticosteroid-responsive condition}

\section{To the Editors:}

Few areas of respiratory medicine have generated as much controversy as the use and purpose of long-term corticosteroid treatment in chronic obstructive pulmonary disease (COPD). However, several recent large, placebo-controlled studies have clarified the role of long-term treatment with inhaled corticosteroids [1-3]. There is now consistent evidence that inhaled corticosteroid treatment, even in high doses, is not associated with a clinically significant reduction in the rate of decline of forced expiratory volume in one second (FEV1). Treatment is associated with a modest reduction in the 